\title{
GLL
}

$0 \square=0$ Geomatics, Landmanagement and Landscape No. $2 \cdot 2021,23-37$

\section{POINT POSITION ACCURACY IN A VECTOR GNSS NETWORK AND THE WAY IT IS LINKED TO REFERENCE STATIONS}

\author{
Tadeusz Gargula
}

\section{Summary}

The aim of this study is to assess the impact of the location (distribution) of reference points (reference stations of the ASG-EUPOS system) on the accuracy of the final determination of the local measurement grid points. The research was carried out in terms of the possibility of using the static GNSS method to determine displacements, both relative (vector lengths) and absolute (coordinates in the spatial system). A mathematical record of the computational process (functional model and stochastic model) was presented, on the basis of which the test vector network was adjusted (indirect method) and the accuracy assessment after the adjustment was performed. The subject of the numerical tests were the actual measurement results of a part of the geodetic network (GNSS vectors) established in the mining area (the results of one of the periodic measurement cycles were used). Numerical analyses take into account several different variants of establishing the network: depending on the location (direction east-west, north-south) and the number of ASG-EUPOS stations used. The following parameters (relating to the designated positions) were adopted as comparative criteria: coordinate deviation (in the Cartesian geocentric system) from the reference values, spatial length deviation between the designated points from its reference value, mean coordinate errors, error in the position of a point in three-dimensional space, length mean error as a function of adjusted observations (using the law of transfer of errors of mean correlated quantities). Particular attention was paid to the discrepancy between the adjustment results for different systems of reference to the ASG-EUPOS stations. On the basis of the performed calculation tests and the performed comparative analyses, conclusions were compiled that may be helpful in planning periodic measurements for the purpose of determining land displacements.

\section{Keywords}

GNSS vector network $\bullet$ establishing a geodetic control network • ASG-EUPOS reference station - rigorous adjustment $\bullet$ determining terrain displacements

\section{Introduction}

The technique of GNSS satellite measurements gives the opportunity to easily connect the measurement object with the geodetic network, thanks to the possibility of using vectors of any length. This is important, for example, when determining absolute 
displacements in areas prone to displacement [Góral and Szewczyk 2004, Baryła et al. 2007, Wiśniewski and Kamiński 2020]. Such possibilities of establishing the network are provided by the ASG-EUPOS system [Bosy et al. 2008], whose main function is to ensure a uniform (nationwide) system of spatial references. According to the studies [GUGIK 2011, 2013], the accuracy of determining the coordinates when using computing services (e.g. POZGEO [Pażus 2009]) available in this system is $0.01 \mathrm{~m}$ for the static method, however, the actual accuracy also depends on the type of measuring equipment, observation time, post-processing software, etc. - the actual error in determining the position may range from a few to over a dozen centimetres. The research conducted by the authors of the study [Dawidowicz et al. 2007] shows, however, that determining a point height with an accuracy of 1-2 cm with long vectors (of ca. $20 \mathrm{~km}$ ) requires long observation sessions (over two hours), which in turn is associated with a greater cost of measurement. Manufacturers of GNNS receivers [Leica 2009] adopt the following principle of determining the accuracy of the position using the static method: $5-10 \mathrm{~mm}+0.5 \mathrm{ppm}$ (for example, for a vector of $50 \mathrm{~km}$ it gives approx. \pm $3 \mathrm{~cm}$ ). The author of another paper [Kadaj 2007] claims, however, that long GNNS vectors are characterised by constant (sub-centimetre) accuracy and therefore they constitute a simple method of improving the structure of classical networks in terms of absolute accuracy and reliability. A fundamental question arises here: does the GNSS measurement technology (using the ASG-EUPOS system) really lead to a qualitative improvement of the entire observation system in any situation? For displacement measurements, precise situational and height measurements are required (using total stations), while in order to determine settlements, geometric levelling (precise or technical) with mean errors in the height difference measurement below $0.1 \mathrm{~mm}$ [Bałut 1997, Prószyński and Kwaśniak 2006].

As it is known, long GNSS vectors used with reference to reference stations (in the order of several dozen kilometres) are burdened with significant errors, both in terms of the vector length and its orientation in space [Kadaj 2007]. Measurement errors, in turn, decide on the accuracy of position determination (mean error of the point position) and indirectly affect the precision of the values determined as a function of the coordinates of the points (e.g. the distance between the points). The obtained accuracy of the determinations may, consequently, determine the necessity to choose a different measurement method that meets the assumed requirements, even in spite of the greater costs and labour-intensity of field work.

As part of the research carried out in the course of the work [Gargula 2011], a series of numerical tests were carried out in terms of determining displacements (on two test objects), and the analysis of the obtained results allowed, inter alia, to determine a certain relationship between the conditions of referencing the ASG-EUPOS network points (e.g. the number of points or the directions of their location in relation to the object) and the parameters describing the position (relative and absolute) of the points of the tested control network. This paper is an attempt to continue this research. Similar research issues were also undertaken in other studies, e.g. [Gargula 2009, 2010, 2011a, 2019]. 


\section{Description of the research performed}

The test object was a part of the control network (Fig. 1a: side 4-5), measured with reference to the reference points KATO, KRAW, ZYWI and WODZ (of the ASG-EUPOS system). The vectors between the studied points (4-5) and the reference vectors (to the reference points) were measured using the GNSS static method (2 receivers, measurement time: 60 minutes). The control network was established to study the displacements of the area in the mining area (close to Chełm Sląski, near Katowice). Figure 1 shows several research variants $\left(V_{-} 1 \div V_{-} 6\right)$, differing in the way the test section is linked to the reference points:

- Option V_1: reference to 4 points in E, W, N, S directions (E - east, W - west, N north, $\mathrm{S}$ - south);

- Variant V_2: reference to 3 points in W, N, S directions;

- Variant V_3: reference to 2 points in N, S directions;

- Variant V_4: reference to 2 points in W, N directions;

- Variant V_5: reference to 1 point in the $\mathrm{N}$ direction;

- Variant V_6: Reference to 2 points in E, W directions.

For the purposes of this study, the results of measurements (Table 1), necessary for the implementation of variant V_1 (Fig. 1a), obtained on the basis of postprocessing (GNSS vectors and their mean errors) were used. To complete the set of output data, the coordinates of the reference stations and the approximate coordinates of the designated points (necessary to adjust the observations using the indirect method, according to the least squares procedure) were also compiled (in Table 2).

Table 1. List of observations to be adjusted and their mean errors

\begin{tabular}{|c|c|c|c|c|c|c|c|}
\hline \multicolumn{2}{|c|}{$\begin{array}{l}\text { Vector } \\
\text { markings }\end{array}$} & \multicolumn{3}{|c|}{$\begin{array}{l}\text { Observations (components of GNSS vectors) } \\
{[\mathrm{m}]}\end{array}$} & \multicolumn{3}{|c|}{$\begin{array}{l}\text { Mean errors of observations } \\
{[\mathrm{m}]}\end{array}$} \\
\hline From & To & $\Delta \mathrm{X}$ & $\Delta \mathrm{Y}$ & $\Delta \mathrm{Z}$ & $m_{\Delta X}$ & $m_{\Delta Y}$ & $m_{\Delta Z}$ \\
\hline 5 & 4 & -1.5898 & 23.8237 & -5.1855 & 0.0066 & 0.0051 & 0.0052 \\
\hline KATO & 4 & 8881.6840 & 13105.5420 & -10642.9751 & 0.0055 & 0.0043 & 0.0047 \\
\hline KATO & 5 & 8883.2690 & 13081.7339 & -10637.7916 & 0.0166 & 0.0131 & 0.0143 \\
\hline KRAW & 4 & 14937.9164 & -51822.2599 & 2743.0312 & 0.0064 & 0.0053 & 0.0060 \\
\hline KRAW & 5 & 14939.4976 & -51846.0695 & 2748.2310 & 0.0094 & 0.0080 & 0.0085 \\
\hline WODZ & 4 & -24824.6801 & 45254.5225 & 7433.1278 & 0.0062 & 0.0051 & 0.0057 \\
\hline WODZ & 5 & -24823.1195 & 45230.6841 & 7438.3197 & 0.0158 & 0.0139 & 0.0138 \\
\hline ZYWI & 4 & -32759.2432 & -14263.6766 & 29831.6776 & 0.0104 & 0.0073 & 0.0085 \\
\hline ZYWI & 5 & -32757.6232 & -14287.4916 & 29836.8737 & 0.0106 & 0.0063 & 0.0072 \\
\hline
\end{tabular}




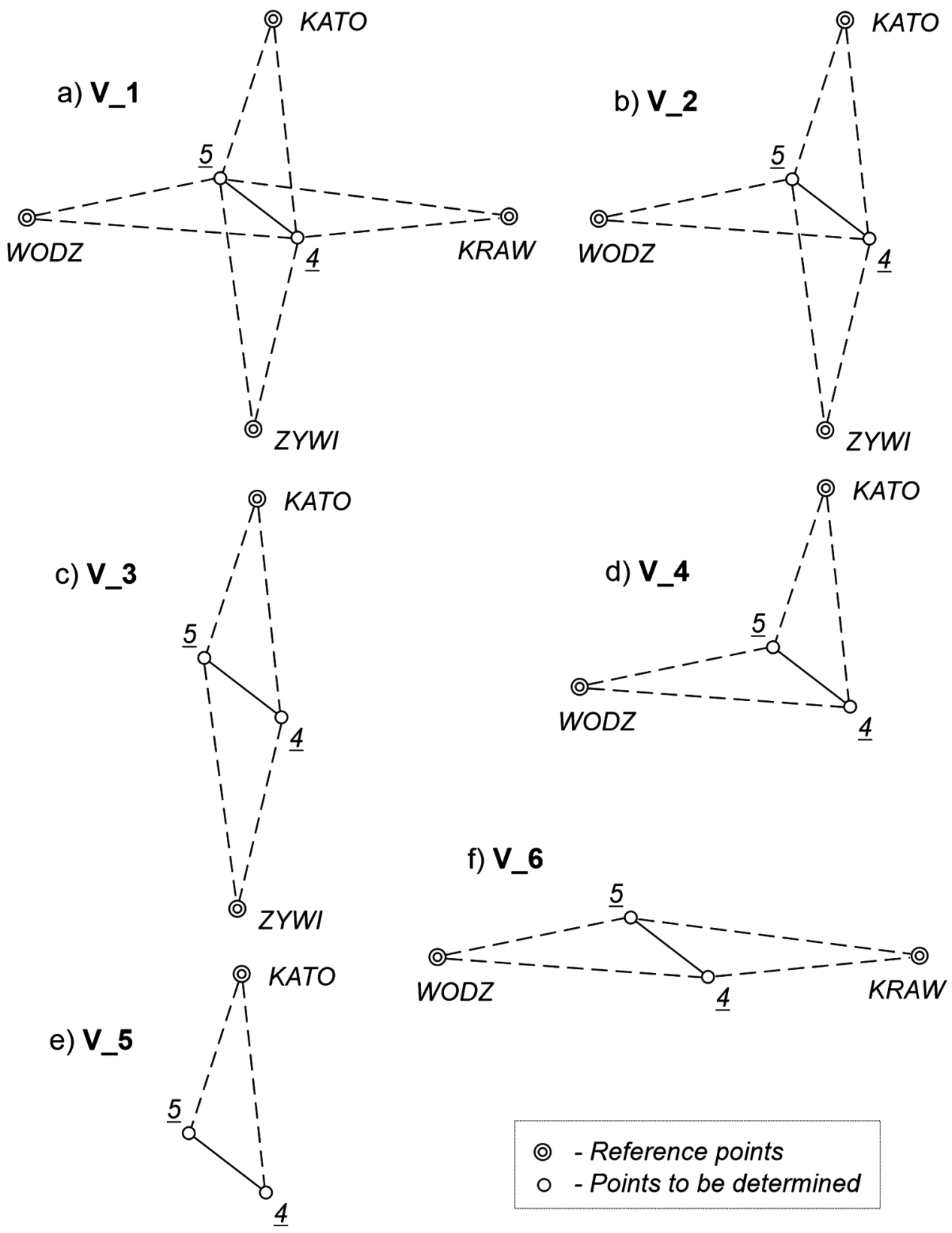

Fig. 1. Research variants (a-f) 
Table 2. Coordinates of reference stations (KATO, KRAW, WODZ, ZYWI) and approximate coordinates $\left({ }^{*}\right)$ of the points to be determined $(4,5)$ - ETRF' 89 geocentric system

\begin{tabular}{|c|c|c|c|}
\hline Point & $\mathrm{X}[\mathrm{m}]$ & $\mathrm{Y}[\mathrm{m}]$ & $\mathrm{Z}[\mathrm{m}]$ \\
\hline KATO & 3862992.3806 & 1332822.6741 & 4881105.4573 \\
\hline KRAW & 3856936.1743 & 1397750.4815 & 4867719.4488 \\
\hline WODZ & 3896698.7807 & 1300673.7066 & 4863029.3737 \\
\hline ZYWI & 3904633.3207 & 1360191.8920 & 4840630.7894 \\
\hline $4^{*}$ & 3871874.0646 & 1345928.2161 & 4870462.4822 \\
\hline $5^{*}$ & 3871875.6496 & 1345904.4080 & 4870467.6657 \\
\hline
\end{tabular}

The aim of each of the research variants (Fig. 1) was to adjust the given observation system and determine the coordinates of the points 4,5 . The adjustment results also made it possible to calculate the spatial length of the side 4-5 (used as a comparative parameter when monitoring the relative displacements in successive cycles of periodic measurements) and to analyse the accuracy of the determined values (mean errors of coordinates and length).

The mathematical record of the adjustment process (functional model) and accuracy assessment (stochastic model) will be presented below.

The adjustment of the vector GNSS network according to the intermediary method begins with the compilation of the observational equations for the three components of each $j-k$ vector:

$$
\begin{gathered}
\left\{\begin{array}{l}
\Delta x_{j k}+v_{j k}^{(\Delta x)}=x_{k}-x_{j} \\
\Delta y_{j k}+v_{j k}^{(\Delta y)}=y_{k}-y_{j} \\
\Delta z_{j k}+v_{j k}^{(\Delta z)}=z_{k}-z_{j}
\end{array}\right. \\
\left\{\begin{array}{l}
v_{j k}^{(\Delta x)}=\delta x_{k}-\delta x_{j}+l_{j k}^{(\Delta x)} \\
v_{j k}^{(\Delta y)}=\delta y_{k}-\delta y_{j}+l_{j k}^{(\Delta y)} \\
v_{j k}^{(\Delta z)}=\delta z_{k}-\delta z_{j}+l_{j k}^{(\Delta z)}
\end{array}\right. \\
\left\{\begin{array}{l}
l_{j k}^{(\Delta x)}=\Delta x_{j k}^{(0)}-\Delta x_{j k} \\
l_{j k}^{(\Delta y)}=\Delta y_{j k}^{(0)}-\Delta y_{j k} \\
l_{j k}^{(\Delta z)}=\Delta z_{j k}^{(0)}-\Delta z_{j k}
\end{array}\right.
\end{gathered}
$$




$$
\left\{\begin{array}{l}
\Delta x_{j k}^{(0)}=x_{k}^{(0)}-x_{j}^{(0)} \\
\Delta y_{j k}^{(0)}=y_{k}^{(0)}-y_{j}^{(0)} \\
\Delta z_{j k}^{(0)}=z_{k}^{(0)}-z_{j}^{(0)}
\end{array}\right.
$$

where:

$l^{(\Delta x)}, l^{(\Delta y)}, l^{(\Delta z)} \quad$ - absolute terms in correction equations (2),

$v^{(\Delta x)}, v^{(\Delta y)}, v^{(\Delta z)} \quad$ - searched corrections to component elements of the GNSS vector,

$\Delta x^{(0)}, \Delta y^{(0)}, \Delta z^{(0)}$ - approximate values of the vector components,

$\delta x, \delta y, \delta z \quad$ - searched increments (corrections) to approximate coordinates,

$x^{(0)}, y^{(0)}, z^{(0)} \quad$ - approximate coordinates.

The system of correction equations (2) is written in the matrix form:

$$
\mathbf{V}=\mathbf{A} \cdot \mathbf{X}-\mathbf{L}
$$

where:

$\mathbf{V}=\left[\left\{v_{j k}^{(\Delta x)} ; v_{j k}^{(\Delta y)} ; v_{j k}^{(\Delta z)}\right\}\right]^{T} \quad \quad-$ vector of determined corrections,

A - matrix of coefficients with unknowns, in this case these coefficients are: 1 (for the end point $k$ ) or -1 (for the starting point $j$ ),

$\mathbf{X}=\left[\left\{\delta x_{j} ; \delta y_{j} ; \delta z_{j} ; \delta x_{k} ; \delta y_{k} ; \delta z_{k}\right\}\right]^{T}-\begin{aligned} & \text { vector of unknowns, i.e. increments to appro- } \\ & \text { ximate coordinates, }\end{aligned}$

$\mathbf{L}=\left[\left\{l_{j k}^{(\Delta x)} ; l_{j k}^{(\Delta y)} ; l_{j k}^{(\Delta z)}\right\}\right]^{T} \quad \quad-$ vector of absolute terms (11).

The estimated vector of unknowns $\hat{\mathbf{X}}$ is calculated using the method known from the adjustment calculus [Wiśniewski 2005], resulting from the imposition of the least squares condition $\left(\mathbf{V}^{\mathrm{T}} \cdot \mathbf{P} \cdot \mathbf{V}=\mathbf{m i n}\right.$.) on the system (5):

$$
\hat{\mathbf{X}}=\left(\mathbf{A}^{\mathrm{T}} \cdot \mathbf{P} \cdot \mathbf{A}\right)^{-1} \cdot \mathbf{A}^{\mathrm{T}} \cdot \mathbf{P} \cdot \mathbf{L}
$$

where $\mathbf{P}$ is the weight (diagonal) matrix, compiled on the basis of errors of mean a priori of vector components $\left(m_{j k}^{(\Delta x)}, m_{j k}^{(\Delta y)}, m_{j k}^{(\Delta z)}\right)$ :

$$
\mathbf{P}=\operatorname{diag}\left\{\frac{1}{\left(m_{j k}^{(\Delta x)}\right)^{2}} ; \frac{1}{\left(m_{j k}^{(\Delta y)}\right)^{2}} ; \frac{1}{\left(m_{j k}^{(\Delta z)}\right)^{2}}\right\}
$$

The next step is to substitute the vector $\hat{\mathbf{X}}$ (6) for the vector of unknowns $\mathbf{X}$ (5) and calculate the vector of observational corrections $\mathbf{V}$, which, in turn, provide the basis for adjusting the observations - the left side of the observation equations (1). 
Information about errors in the means of the adjusted coordinates $\left(m_{x}, m_{y}, m_{z}\right)$ can be found on the diagonal of the covariance matrix of the vector $\mathbf{X}$ :

$$
\begin{gathered}
\mathbf{Q}_{x}=m_{0} \cdot\left(\mathbf{A}^{\mathbf{T}} \cdot \mathbf{P} \cdot \mathbf{A}\right)^{-1} \rightarrow \operatorname{diag}\left\{\mathbf{Q}_{x}\right\}=\left\{m_{x} ; m_{y} ; m_{z}\right\} \\
m_{0}=\sqrt{\frac{\mathbf{V}^{\mathbf{T}} \cdot \mathbf{P} \cdot \mathbf{V}}{r}}
\end{gathered}
$$

where:

$m_{0}$ - mean unit error of observations,

$r$ - the number of oversized observations.

Then, for each designated point, a single parameter characterising its accuracy will be calculated - the error of the point location in the spatial Cartesian system:

$$
m_{p}=\sqrt{m_{x}^{2}+m_{y}^{2}+m_{z}^{2}}
$$

Since we are also interested in the relative (mutual) position of the points to be determined, then on the basis of adjusted observations $(\overline{\Delta x}, \overline{\Delta y}, \overline{\Delta z})$ we calculate the spatial distance (generally: for points $j-k$, in our example: $4-5$ ):

$$
d_{j k}=\sqrt{\left(\overline{\Delta x}_{j k}\right)^{2}+\left(\overline{\Delta y}_{j k}\right)^{2}+\left(\overline{\Delta z}_{j k}\right)^{2}}
$$

To estimate the accuracy of determined distance $j-k$ the law of transfer of mean errors for correlated quantities [Wiśniewski 2005] is applied:

$$
m_{j k}^{(d)}=\sqrt{\left(\frac{\partial d_{j k}}{\partial\left(\Delta x_{j k}\right)}\right)^{2} \cdot\left(m_{j k}^{(\Delta x)}\right)^{2}+\left(\frac{\partial d_{j k}}{\partial\left(\Delta y_{j k}\right)}\right)^{2} \cdot\left(m_{j k}^{(\Delta y)}\right)^{2}+\left(\frac{\partial d_{j k}}{\partial\left(\Delta z_{j k}\right)}\right)^{2} \cdot\left(m_{j k}^{(\Delta z)}\right)^{2}}
$$

After calculating the partial derivatives ( $\partial$ symbol) with respect to the individual variables ( $j k$ vector components), we obtain the final formula:

$$
m_{j k}^{(d)}=\frac{\sqrt{\left(\Delta x_{j k}\right)^{2} \cdot\left(m_{j k}^{(\Delta x)}\right)^{2}+\left(\Delta y_{j k}\right)^{2} \cdot\left(m_{j k}^{(\Delta y)}\right)^{2}+\left(\Delta z_{j k}\right)^{2} \cdot\left(m_{j k}^{(\Delta z)}\right)^{2}}}{d_{j k}}
$$

The calculation procedure written with the formulas (1) $\div(13)$ was carried out (for the planned test variants) with the use of formulas developed in MS Excel. 


\section{Analysis of the results}

As a result of the adjustment of the test networks in individual variants, the coordinates of the control network points and the spatial distance were obtained (Table 3 - for the purposes of comparative analysis, these data were recorded with a precision of $0.0001 \mathrm{~m}$ ). Coordinate and length deviations (in relation to the initial version $\mathrm{V} \_1$, where the highest number of reference points occur) are summarised in Table 4 and illustrated in graphs (Fig. 2 and 3).

Table 3. Adjustment results (geocentric coordinates and spatial length)

\begin{tabular}{|c|c|c|c|c|c|c|c|}
\hline \multirow{2}{*}{ Version } & \multicolumn{5}{|c|}{ Point: 4} & \multicolumn{3}{c|}{ Point: 5} & Side: 4-5 \\
\cline { 2 - 8 } & $\mathrm{X}[\mathrm{m}]$ & $\mathrm{Y}[\mathrm{m}]$ & $\mathrm{Z}[\mathrm{m}]$ & $\mathrm{X}[\mathrm{m}]$ & $\mathrm{Y}[\mathrm{m}]$ & $\mathrm{Z}[\mathrm{m}]$ & $d[\mathrm{~m}]$ \\
\hline V_1 & 3871874.0832 & 1345928.2216 & 4870462.4852 & 3871875.6745 & 1345904.4013 & 4870467.6716 & 24.4303 \\
\hline V_2 & 3871874.0811 & 1345928.2210 & 4870462.4860 & 3871875.6739 & 1345904.3987 & 4870467.6704 & 24.4318 \\
\hline V_3 & 3871874.0717 & 1345928.2178 & 4870462.4785 & 3871875.6693 & 1345904.3975 & 4870467.6639 & 24.4304 \\
\hline V_4 & 3871874.0792 & 1345928.2217 & 4870462.4904 & 3871875.6657 & 1345904.3984 & 4870467.6768 & 24.4329 \\
\hline V_5 & 3871874.0642 & 1345928.2174 & 4870462.4820 & 3871875.6534 & 1345904.3956 & 4870467.6673 & 24.4314 \\
\hline V_6 & 3871874.0933 & 1345928.2263 & 4870462.4925 & 3871875.6775 & 1345904.4040 & 4870467.6799 & 24.4319 \\
\hline
\end{tabular}

Table 4. Coordinate and side length deviations 4-5 (in relation to version V_1)

\begin{tabular}{|c|c|c|c|c|c|c|c|}
\hline \multirow{2}{*}{$\begin{array}{l}\text { Deviations } \\
\text { for } \\
\text { version: }\end{array}$} & \multicolumn{3}{|c|}{ Point: 4} & \multicolumn{3}{|c|}{ Point: 5} & \multirow{2}{*}{ 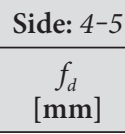 } \\
\hline & $\begin{array}{c}f_{X} \\
{[\mathrm{~mm}]}\end{array}$ & $\begin{array}{c}f_{Y} \\
{[\mathrm{~mm}]}\end{array}$ & $\begin{array}{c}f_{Z} \\
{[\mathrm{~mm}]}\end{array}$ & $\begin{array}{c}f_{X} \\
{[\mathrm{~mm}]}\end{array}$ & $\begin{array}{c}f_{Y} \\
{[\mathrm{~mm}]}\end{array}$ & $\begin{array}{c}f_{Z} \\
{[\mathrm{~mm}]}\end{array}$ & \\
\hline V_2 & -2.1 & -0.7 & 0.8 & -0.5 & -2.6 & -1.3 & 1.5 \\
\hline V_3 & -11.5 & -3.9 & -6.7 & -5.2 & -3.8 & -7.8 & 0.1 \\
\hline V_4 & -4.0 & 0.0 & 5.2 & -8.8 & -2.9 & 5.2 & 2.6 \\
\hline V_5 & -19.0 & -4.2 & -3.2 & -21.1 & -5.7 & -4.3 & 1.1 \\
\hline V_6 & 10.1 & 4.6 & 7.3 & 3.0 & 2.7 & 8.2 & 1.6 \\
\hline
\end{tabular}

Differences between the values of the spatial distance of the side 4-5 (Table 4) are not large - on the order of single millimetres, but they may be significant when examining the relative displacements of the object. The greatest length deviation $(2.6 \mathrm{~mm})$ occurs for the $\mathrm{V} \_4$ variant (a reference to two points: WODZ and KATO), which may suggest errors in measuring vectors for the WODZ station, because for the V_ 5 version with a single reference to the KATO station this deviation is much smaller $(1.1 \mathrm{~mm})$. On the other hand, however, in version V_6 (reference to two points: WODZ and KRAW) the deviation is not very large $(1.6 \mathrm{~mm})$, which does not raise any objections regarding the reference to the WODZ station. The recorded deviations are not correlated with the 


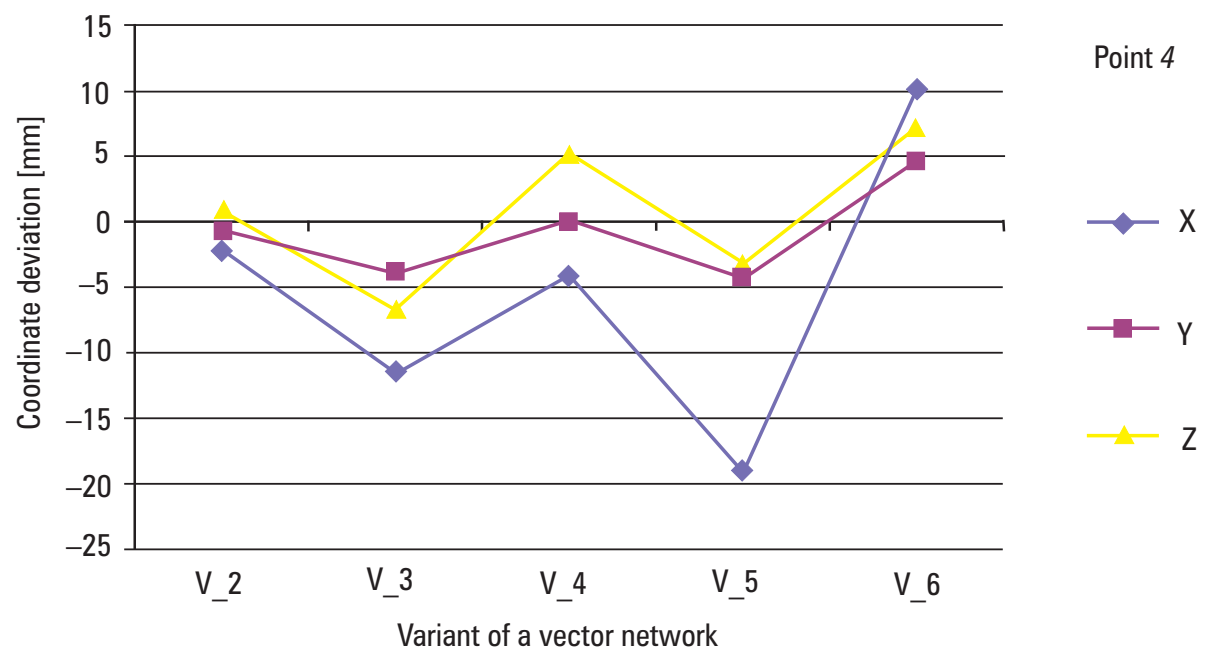

Fig. 2. Coordinate deviations for the point no. 4 (with reference to variant V_1)

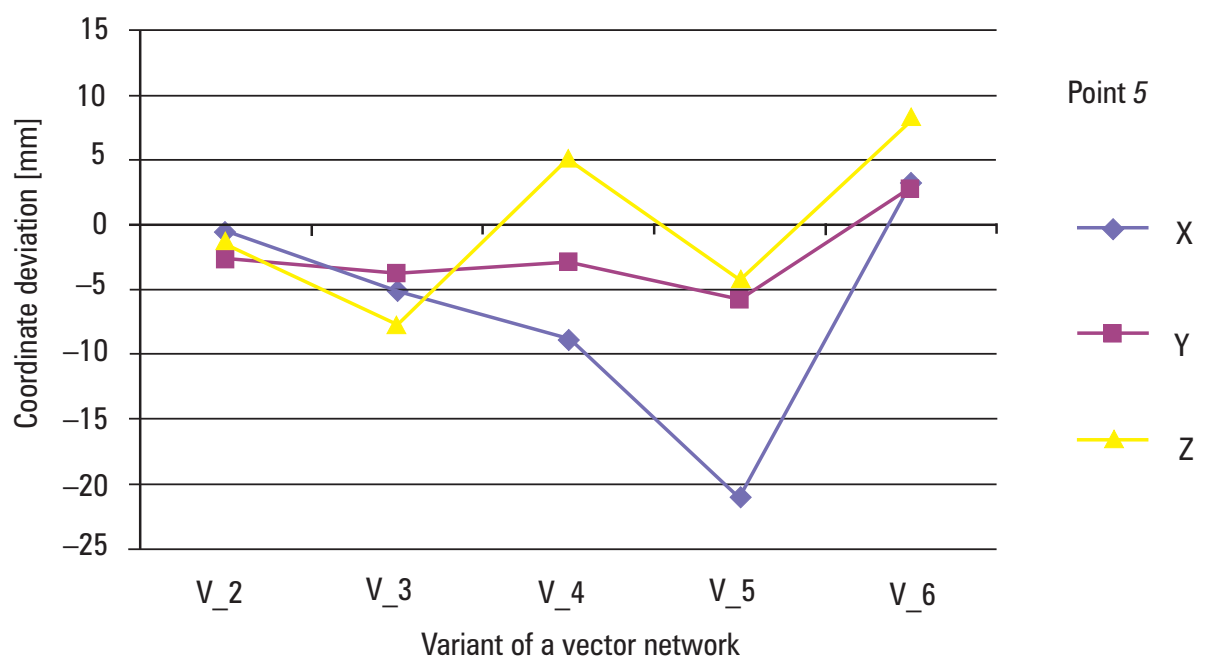

Fig. 3. Coordinate deviations for the point no. 5 (with reference to variant V_1)

number of reference stations used: for versions V_3, V_4 and V_6 (2 stations each), the deviations are differentiated as follows $(\mathrm{mm}): 0,1 ; 2,6 ; 1,6$, respectively. On the other hand, when comparing two variants that differ in the directions of the reference $\left(\mathrm{V} \_3\right.$ and V_6), we notice a quite significant discrepancy $(0.1 \mathrm{~mm}-1.6 \mathrm{~mm})$, which could argue in favour of referring to the N-S directions as a more advantageous option than in the case of the reference in the $\mathrm{C}$-E directions. 
When analysing the values of coordinate deviations (Table 4, Fig. 2 and 3), much greater discrepancies than in the case of length deviations can be noticed. The highest values of deviations (in terms of absolute values) were obtained in the variant $\mathrm{V} \_5$, especially for the X coordinate of approx. $2 \mathrm{~cm}$ - in the case of both points (4 and 5). Errors of this size may significantly distort the results of the absolute displacement test. However, the reasons for such large deviations cannot be found in the errors of a single reference KATO station, as it also occurs in all other variants. When we take into account the length deviation for the V_5 variant - $1.1 \mathrm{~mm}$ - it also cannot be objected to. Comparing the two variants with different reference directions (V_3 and V_6), it can be noticed that the absolute values of the coordinate deviations are similar, but with opposite signs. For example, the X coordinate for the point no. 4 differs in both variants by more than $2 \mathrm{~cm}$, and for $\mathrm{Y}$ - approx. $9 \mathrm{~mm}$. This observation may confirm the theory about the influence of the reference directions (N-S; W-E) on the accuracy of determining the position (similarly to the analysis of length deviations). However, taking into account the number of reference points (V_2 - 3 points; V_4 - 2 points; V_5 - 1 point), a quite clear relationship can be seen: the more reference points, the smaller the deviations. This observation seems quite obvious, but it is not confirmed at the earlier stage of the analysis of deviations for the side length 4-5.

As part of the accuracy assessment after adjustment, the accuracy point parameters were calculated (for points 4 and 5): mean coordinate errors (8) and point position error in space (10). The results of these calculations are presented in Table 5 and illustrated in graphs (Fig. 4 and 5).

Table 5. Accuracy parameters for the determined points (after adjustment)

\begin{tabular}{|c|c|c|c|c|c|c|c|c|}
\hline \multirow{3}{*}{ Version } & \multicolumn{6}{|c|}{ Mean errors of coordinates [mm] } & \multicolumn{2}{|c|}{ Position error $[\mathrm{mm}]$} \\
\hline & \multicolumn{3}{|c|}{ Point: 4} & \multicolumn{3}{|c|}{ Point: 5} & Point: 4 & Point: 5 \\
\hline & $m_{X}$ & $m_{Y}$ & $m_{z}$ & $m_{X}$ & $m_{Y}$ & $m_{Z}$ & $m_{P 4}$ & $m_{P 5}$ \\
\hline V_1 & 5.0 & 3.9 & 4.4 & 7.5 & 5.7 & 6.1 & 7.7 & 11.2 \\
\hline V_2 & 6.5 & 5.0 & 5.6 & 9.9 & 7.1 & 7.7 & 9.9 & 14.4 \\
\hline V_3 & 5.9 & 4.4 & 4.9 & 8.0 & 5.6 & 6.1 & 8.9 & 11.6 \\
\hline V_4 & 7.6 & 6.1 & 6.7 & 12.5 & 9.9 & 10.4 & 11.8 & 19.0 \\
\hline V_5 & 3.3 & 2.6 & 2.8 & 4.8 & 3.8 & 4.0 & 5.1 & 7.3 \\
\hline V_6 & 5.2 & 4.3 & 4.8 & 7.2 & 6.0 & 6.3 & 8.3 & 11.3 \\
\hline
\end{tabular}

Differences in the mean errors of the $\mathrm{X}, \mathrm{Y}, \mathrm{Z}$ coordinates (for individual variants) are small - on the order of 1-2 mm (Table 5). For both, the item no. 4 and the item no. 5 , the values of the considered accuracy parameters differ between individual variants, but they are not large. For example, the greatest difference in the position error occurs between variants V_4 and V_5 - approx. $7 \mathrm{~mm}$ (point 4) and approx. $12 \mathrm{~mm}$ 
(point 5). However, such values may be important when assessing the significance of displacements of the tested object. The above comparison leads to the conclusion that the best solution (in terms of accuracy) is given by the variant V_5 (referring to a single point in the $\mathrm{N}$ direction), and the worst is the variant $\mathrm{V} \_4$ (referring to two points in the directions: W, N) - in this case the position error for item no. 5 is almost $2 \mathrm{~cm}$. The comparative criteria considered do not "fit" so far to such an assessment of these two variants - neither the number of reference points, nor the directions to the reference points (W-E; N-S). This may mean (for example) an inadequate estimation (at the post-processing stage) of the mean errors (a priori) of the measurement of vectors between points of the control network $(4,5)$ and the KATO station (measurement errors translate into errors of values determined on their basis, i.e. coordinate errors). Also note that the accuracy characteristics (mean errors) for point no. 5 are slightly higher (for all variants) than for point no. 4. This may indicate (for example) the differentiation of errors made when positioning the receivers over these points (centring and antenna height measurement errors).

For the spatial length of the test side 4-5, the length error after adjustment $m_{d}(13)$ was also calculated (for individual variants), as well as the length deviation $d$ from its reference value $d_{t}$ (Table 6 , Fig. 6). The reference length $\left(d_{t}\right)$ was determined on the basis of accurate (repeated) classical measurements: horizontal distance measurement using a precision total station; measurement of the difference in height using the precision levelling method (electronic level and invar code staffs).

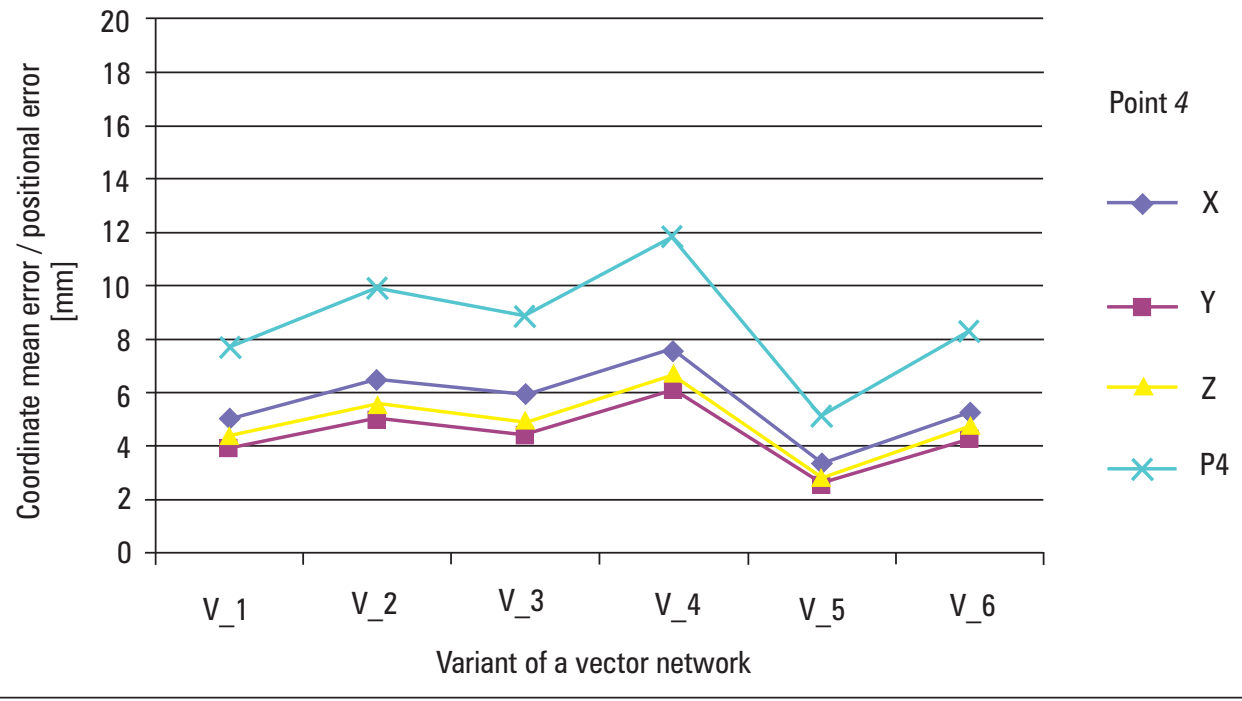

Fig. 4. Point no. 4 location accuracy 


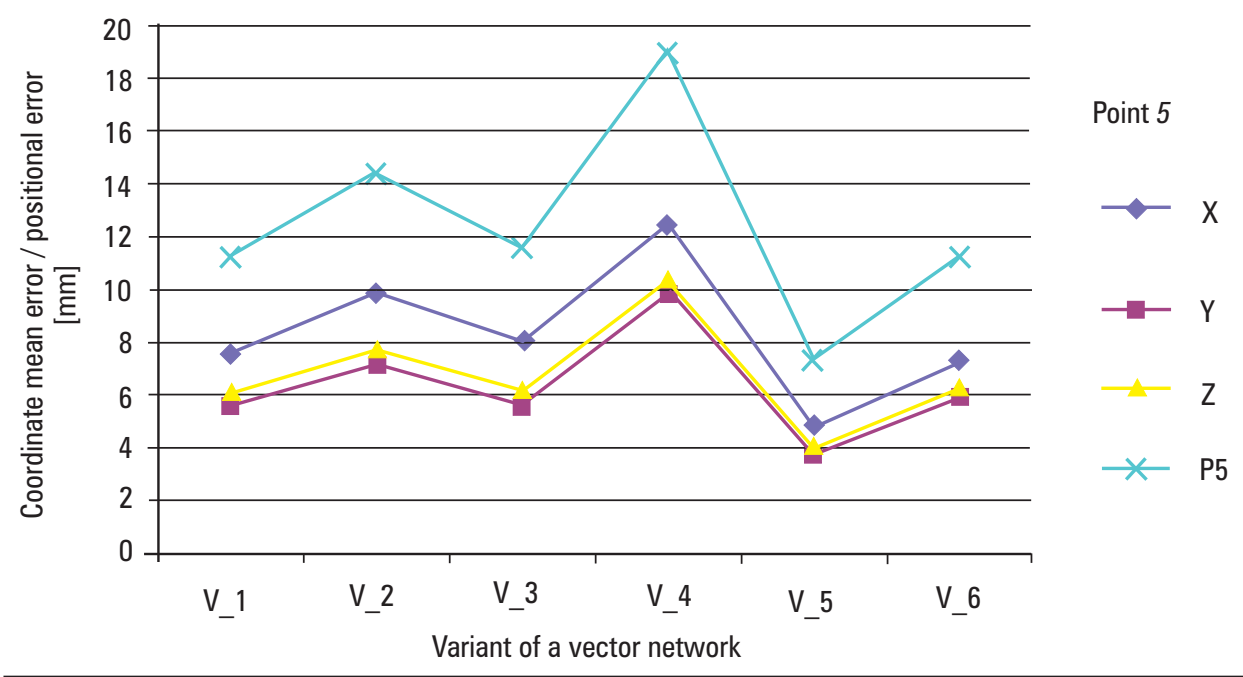

Fig. 5. Point no. 5 location accuracy

Table 6. Analysis of the accuracy of the determined length ( $d$ - tested length, $d_{t}$ - reference length, $m_{d}$ - length mean error after adjustment)

\begin{tabular}{|c|c|c|c|c|}
\hline \multirow{2}{*}{ Version } & \multicolumn{2}{|c|}{ 4-5 side length } & $\begin{array}{c}\text { Length difference } \\
{[\mathrm{m}]}\end{array}$ & $\begin{array}{c}\text { Mean error } \\
{[\mathrm{mm}]}\end{array}$ \\
\cline { 2 - 5 } & $d_{t}$ & $d$ & $\left(d-d_{t}\right)$ & $m_{d}$ \\
\hline V_1 & 24.4403 & 24.4303 & -10.0 & 5.9 \\
V_2 & 24.4403 & 24.4318 & -8.4 & 7.1 \\
V_3 & 24.4403 & 24.4304 & -9.9 & 5.4 \\
V_4 & 24.4403 & 24.4329 & -7.4 & 8.8 \\
V_5 & 24.4403 & 24.4314 & -8.9 & 3.0 \\
V_6 & 24.4403 & 24.4319 & -8.3 & 5.5 \\
\hline
\end{tabular}

The length deviation (determined on the basis of adjusted GNSS vectors) from the reference value (based on classical measurements) is quite large and of a similar value for all variants $(-7 \div-10 \mathrm{~mm})$ - Table 6 . Therefore, assuming that the reference length is error-free, the reasons for these deviations should be found in GNSS measurement errors (e.g. caused by the variability of antenna phase centres - at the points of the control network and at the ASG-EUPOS reference station points). Additionally, the greatest (absolute) deviation is obtained for the variant $V_{-} \_1(10 \mathrm{~mm})$, where the points of the control network were determined based on the largest number of reference points. Thus, this parameter (the $d-d_{t}$ deviation) seems useless for the purpose of the accuracy of determining the test length of the side $4-5$. 


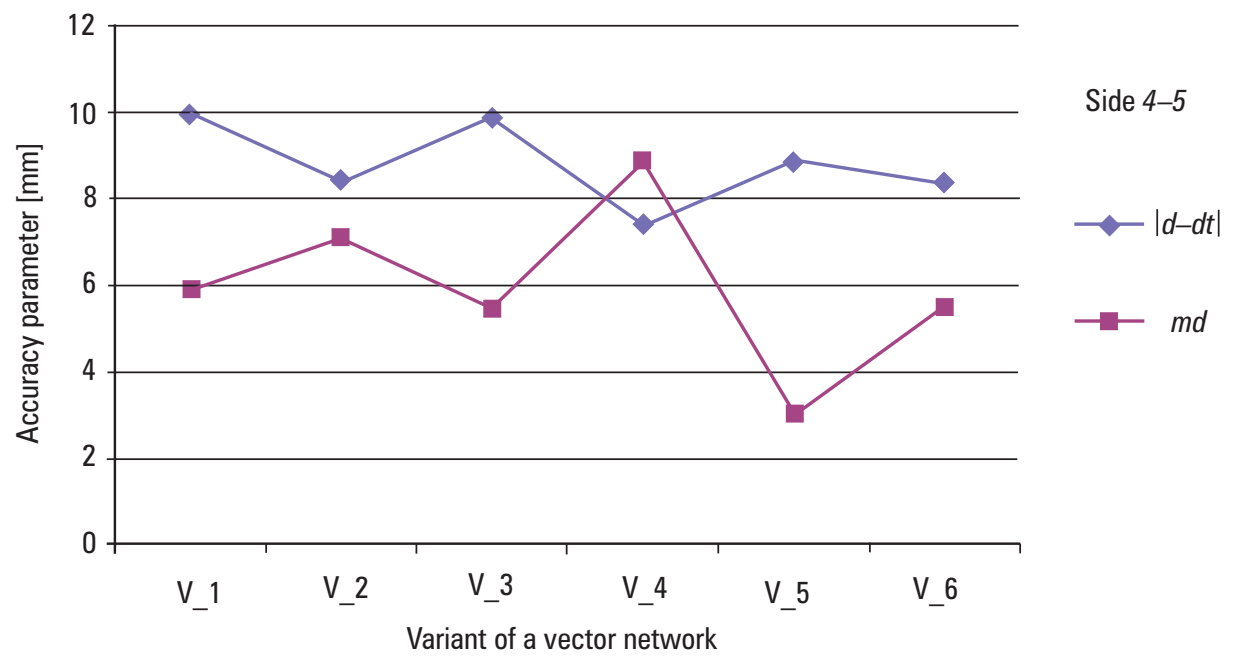

Fig. 6. Accuracy of determining the test length ( $d$ - tested length, $d_{t}-$ reference length, $m_{d}-$ mean length error after adjustment)

Taking into account the error of a posteriori length $m_{d}$ - Table 6), the most favourable should be the variant V_5 (reference to a single station KATO), and the worst - variant V_4 (reference to two stations in the directions: W, N), which correlates with the error values of the position of the points 4, 5 (Table 5). Thus, the conclusions here will be consistent with the results of the previous analysis (Table 5, Fig. 4, 5).

\section{Conclusions}

As a result of independent strict adjustment for each of the six selected test variants, quite significant discrepancies in the coordinates of the designated points were found (up to more than $2 \mathrm{~cm}$ ), as well as some discrepancies in the distance between these points (max. $2.6 \mathrm{~mm}$ ). The individual variants also differ from each other at the stage of assessing the accuracy of the compensated quantities - calculation of mean coordinate errors and position errors (discrepancies up to $12 \mathrm{~mm}$ ) and mean distance errors (discrepancies up to $5 \mathrm{~mm}$ ). Differences of this order should not be underestimated, as they may be important when determining displacements, especially absolute displacements (coordinates).

The reasons for the discrepancies obtained in the results of adjustment and accuracy assessment can be found not only in the conditions of reference to the reference points, but also in the potential errors that occur during the measurement process of the vector network (e.g. antenna centring and measurement errors; variability of antenna phase centres - especially with different types of antennas at the points of the control network and at the points of ASG-EUPOS reference stations; incorrect estimation of the mean errors of vector measurements, etc.). 
On the basis of the performed comparative analyses, no clear relationships were found between the method of establishing the control network to the reference stations (number of stations and their location) and the accuracy of the determinations. For several tested variants, however, the influence of the reference directions (N-S, W-E) on the accuracy of determining the position can be noticed, as well as a quite obvious relationship - the more reference points, the smaller the coordinate deviations. To confirm these conclusions, however, further test studies are needed, carried out for a larger number of (designated) control points and taking into account the detailed conditions of establishing (e.g. control network adjustment based on individual ASG_EUPOS stations - for all possible variants). This research will be continued by the author of this paper.

This paper was funded from a subsidy by the Ministry of Education and Science for the Hugo Kołtataj University of Agriculture in Krakow for the year 2021.

\section{References}

Bałut A., Gocał J. 1997. Precise GPS and classical control for local ground deformations in mining and landslide areas and for project surveys. Reports on Geodesy. Komitet Geodezji PAN, 5(28).

Baryła R., Oszczak S., Koczot B., Szczechowski B. 2007. A concept of using static GPS measurements for determination of vertical and horizontal land deformations in the Main and Old City of Gdansk. Reports on Geodesy, 1(82), 17-24.

Bosy J., Graszka W., Leończyk M. 2008. Aktywna Sieć Geodezyjna EUPOS jako element składowy państwowego systemu odniesień przestrzennych. Przegląd Geodezyjny, Wyd. SIGMA-NOT, 12.

Dawidowicz K., Lamparski J., Świątek K. 2007. Wyznaczanie wysokości z wykorzystaniem niwelacji satelitarnej. XX Jubileuszowa Jesienna Szkoła Geodezji „Współczesne metody pozyskiwania i modelowania geodanych", Polanica Zdrój, 16-18 września 2007 r.

Gargula T. 2009. Wpływ długich wektorów GPS na dokładność pozycji punktu w zastosowaniu do wyznaczania przemieszczeń terenu. Przegląd Geodezyjny, 8, 10-14.

Gargula T. 2010. Application of a damping function in adjustment of GPS networks with long vectors. Allgemeine Vermessung-Nachrichten, 2, 62-70.

Gargula T. 2011. Zintegrowane sieci modularne w zastosowaniu do wyznaczania przemieszczeń. Zeszyty Naukowe UR w Krakowie, 473, seria Rozprawy, 350.

Gargula T. 2011a. GPS Vector Network Adjustment in a Local System of Coordinates Based on Linear-Angular Spatial Pseudo-Observations. Journal of Surveying Engineering, 137(2), 60-64.

Gargula T. 2019. The concept for numerical development of modular networks integrated with the GNSS measurements, Geomatics, Landmanagement and Landscape, 1, 15-23

Góral W., Szewczyk J. 2004. Zastosowanie technologii GPS w precyzyjnych pomiarach deformacji. Uczelniane Wyd. Nauk.-Dyd. AGH, Kraków.

GUGiK 2011. Zalecenia techniczne: Pomiary satelitarne oparte na systemie precyzyjnego pozycjonowania ASG-EUPOS (www.asgeupos.pl).

GUGiK 2013. Poradnik użytkownika systemu ASG-EUPOS. Warszawa (www.asgeupos.pl).

Kadaj R. 2007. Sieci wektorowe GPS z obserwacjami klasycznymi w aspekcie modernizacji państwowych osnów geodezyjnych. Zeszyty Naukowe Politechniki Rzeszowskiej. Budownictwo i Inżynieria Środowiska, 1, 171-178. 
Leica 2009. Leica GPS1200 - Specyfikacja techniczna i charakterystyka systemu (www.leica-geosystems.com).

Pażus R. 2009. Spojrzenie na ASG-EUPOS od strony użytkownika POZGEO. Cz. III. Raport POZGEO. Geodeta - Magazyn Geoinformacyjny, 5(168), 26-28.

Prószyński W., Kwaśniak M. 2006. Podstawy geodezyjnego wyznaczania przemieszczeń. Pojęcia i elementy metodyki. Oficyna Wydawnicza Politechniki Warszawskiej, Warszawa.

Wiśniewski Z. 2005. Rachunek wyrównawczy w geodezji (z przykładami). Wyd. Uniwersytetu Warmińsko-Mazurskiego, Olsztyn.

Wiśniewski Z., Kamiński W. 2020. Estimation and Prediction of Vertical Deformations of Random Surfaces. Applying the Total Least Squares Collocation Method. Sensors, 20, 1-24.

\footnotetext{
Dr hab. inż. Tadeusz Gargula

University of Agriculture in Krakow

Division of Land Surveying

ul. Balicka 253, 30-198 Kraków

e-mail: tadeusz.gargula@urk.edu.pl

ORCID: 0000-0003-3109-5922
} 